\title{
TOLERANCIA A INFESTACIÓN POR GORGOJOS (Sitophilus spp.) EN GENOTIPOS DE MAÍZ COMUNES Y DE ALTA CALIDAD PROTEÍNICA ${ }^{1}$
}

\author{
Artemio Palafox-Caballero', Mauro Sierra-Macías ${ }^{2}$, Alejandro Espinosa-Calderón $n^{3}$, \\ Flavio Rodríguez, Montalvo ${ }^{2}$,Enrique Noe Becerra-Leor ${ }^{2}$
}

\begin{abstract}
RESUMEN
Tolerancia a infestación por gorgojos (Sitophilus spp.) en genotipos de maíz comunes y de alta calidad proteínica. Se estableció un experimento en el Campo Experimental Cotaxtla del INIFAP, en el estado de Veracruz, México, durante el ciclo primavera-verano del año 2002, con el objetivo de determinar la producción de genotipos de maíz y el daño causado por gorgojos (Sitophilus spp). Se evaluaron cinco genotipos comunes y 14 de alta calidad de proteína (QPM) en un diseño estadístico de bloques al azar con dos repeticiones. Se registraron y analizaron el rendimiento de grano, la sanidad de la mazorca, el porcentaje de mazorcas con mala cobertura y el porcentaje de mazorcas dañadas por gorgojos. Esta última variable se midió durante cinco meses, en diferentes fechas de cosecha y en mazorcas almacenadas. Se detectaron diferencias significativas en todas las variables excepto la sanidad de la mazorca. El rendimiento de tres genotipos fue sobresaliente: H-520 (7,93 t/ha) y SINT $9(7,11 \mathrm{t} / \mathrm{ha})$ comunes y el H-553C (7,01 t/ha) de alta calidad de proteína; los tres presentaron bajo porcentaje de mazorcas con mala cobertura (menor a 5\%). El daño por gorgojos fue significativamente mayor conforme la cosecha se realizó más tardíamente, incrementándose de $0,19 \%$ en enero a $76,80 \%$ en mayo. Los genotipos menos afectados en el campo fueron H-519C, H-363C y VS-536, con daños inferiores a $2 \%$. Después de cinco meses de almacenamiento, H-363C y SINT9 presentaron daños menores al $70 \%$, mientras que el resto de los genotipos presentaron daños mayores a $90 \%$.
\end{abstract}

Palabras clave: Zea mays L., maíces QPM, híbridos, variedades, Sitophilus spp.

\begin{abstract}
Tolerance to flour beetle (Sitophilus spp.) damage in common and high quality protein maize genotypes. A field experiment was carried out during the spring and summer seasons of 2002 at Cotaxtla Experimental Station, in Veracruz State Mexico, to determine the yield and agronomic characteristics of tropical corn genotypes and the damage caused by flour beetle (Sitophilus spp). Five common and 14 high quality protein maize genotypes (QPM) were evaluated using a random block design with two replications. Grain yield, percentage of rotten ears, husk cover and ear damages by flour beetle in storage and in the field were evaluated. The damage was measured for five months at different harvest times and in stored ears. There were significant differences in all traits, except number of rotten ears. Highest yields were recorded in three genotypes: the two common genotypes $\mathrm{H}$ 520 (7.93 t/ha) and SINT 9 (7.11 t/ha), and the high quality protein hybrid H-553C (7.01 t/ha). These hybrids showed good husk cover, but damage was significantly higher as the harvest date was delayed, increasing from $0.19 \%$ in January to $76.8 \%$ in May. The genotypes less susceptible to damage under field conditions were H-519C, H-363C and VS-536 (less than 2\%). After five months of storage, H-363C and SINT9 experienced less than $70 \%$ damage, while the other genotypes presented damages higher than $90 \%$.
\end{abstract}

Key words: Zea mays, quality protein maize, hybrids, varieties, Sitophilus spp.

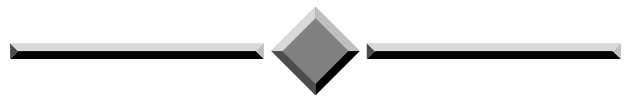

Recibido: 15 de mayo, 2007. Aceptado: 18 de enero, 2008. Presentado en la LIII Reunión del PCCMCA, Antigua, Guatemala. 2007.

2 Campo Experimental Cotaxtla, INIFAP. Km. 34 Carret. Veracruz-Córdoba. Apdo. Postal 429. CP 91700. Veracruz, México. Tel: 012299342926. Correo electrónico: palafox.artemio@inifap.gob.mx

3 Campo Experimental Valle de México, INIFAP. Km 18.5 carretera Los Reyes-Lechería, Apdo. Postal 10, 56230, Chapingo, Texcoco, Edo. de México, México. 


\section{INTRODUCCIÓN}

En el área tropical de México se siembran anualmente tres millones de hectáreas con maíz, que representan el $40 \%$ de la producción total nacional. En el estado de Veracruz se siembran anualmente cerca de 800.000 hectáreas con maíz, que aportan 1.623 .000 toneladas de grano. El 80\% de la cosecha se destina al autoconsumo principalmente enfocado a los molineros de la región. El 65\% del volumen producido en este estado se cosecha en la región tropical, donde las condiciones de alta humedad relativa y altas temperaturas favorecen la presencia de plagas de los granos, principalmente del género Sitophilus. El problema es mayor debido a que los productores de maíz no cuentan con infraestructura para el secado de su producto, por lo que cosechan hasta que el grano es secado en la planta hasta alcanzar un 12 a $14 \%$ de humedad; posteriormente el grano destinado al autoconsumo es almacenado en tanques de metal y el resto vendido al molinero o intermediario. Esta situación hace que el grano quede expuesto por mucho tiempo en el campo al daño por gorgojos y que se generen pérdidas de alrededor de $25 \%$ del volumen producido.

En el maíz común, el endospermo contiene $90 \%$ de almidón y $90 \%$ de la proteína del grano, mientras que el germen contiene $30 \%$ de aceite y $10 \%$ de proteína. De 60 a 70\% de la proteína se encuentra en forma de zeína, y es deficiente en lisina y triptofano, que son aminoácidos esenciales para crecimiento y desarrollo humano. Se ha descubierto que el gene opaco-2, en su versión homocigótica recesiva, permite duplicar la cantidad de dichos aminoácidos y darle un valor nutritivo superior, en comparación con el maíz común (Ortega et al. 2001). A pesar de que el contenido proteínico del grano de maíz es bajo, proporciona en promedio 39\% de proteína y el 59\% de la energía que ingieren los mexicanos.

En 1964 un grupo de científicos de la Universidad de Purdue descubrieron dos genes independientes, opaco-2 y harinoso-2, que incrementan notablemente el contenido de lisina y de triptofano. Estos científicos señalan que "el maíz con el gene opaco- 2 contiene de $69 \%$ a $100 \%$ más lisina y $66 \%$ más triptofano que el maíz normal" (Reyes 1971).

El Centro Internacional de Mejoramiento de Maíz y Trigo (CIMMYT 1999) desarrolló un proceso de conversión del opaco-2 e indicó el efecto que tiene este gene sobre los materiales convertidos. La transferencia del gene opaco-2 a las variedades normales de maíz duro y hendido cambia la apariencia física del grano y lo convierte en grano opaco. Al alto valor nutritivo de estos maíces se ligaban características indeseables como: granos con textura suave, bajo peso, poca resistencia a enfermedades y plagas; problemas que limitaron el avance de estas investigaciones (Mertz et al. 1964). Por su parte Vasal et al. (1980), incorporaron al maíz opaco genes modificadores de la textura del endospermo, los cuales aportan al grano mayor dureza que el maíz opaco, dando la apariencia de un maíz común; obteniendo así en la década de los 80s lo que se conoce como "maíz con alta calidad de proteína" o QPM (del término en inglés quality protein maize).

Los insectos principales que atacan los granos de maíz y otros cereales, por ser altamente destructivo y por encontrarse ampliamente distribuido por el mundo, son el género Sitophilus, con varias especies y el género Sitotroga (Ortega et al. 2001, Villacís et al. 1972). El daño que ocasionan estos insectos es más grave en los trópicos secos y húmedos, donde las condiciones ambientales favorecen su reproducción, que en pocas semanas causa daños del orden de $25 \%$ en la calidad del grano o de la semilla (Lagunas y Domínguez 1985). El problema se ha tratado de resolver mediante el control químico, el cual resulta desventajoso porque genera incremento en los costos, contaminación del producto y deterioro del ambiente (McGregor 1980). Una mejor alternativa de solución es el mejoramiento genético mediante evaluaciones del germoplasma, con el fin de encontrar e incorporar fuentes de resistencia a las variedades mejoradas, pues la infestación principal por gorgojos inicia cuando el grano se encuentra en la etapa de estado lechoso (Ramayo 1983). Beck (1965) menciona que existe la posibilidad de que un material genético no sea preferido por los insectos para ovipositar, debido a sus propiedades intrínsecas. Al respecto, Betanzos (1980) indica que es posible asociar la preferencia alimenticia y reproductiva de los insectos con el contenido químico y las características físicas del grano. $\mathrm{Al}$ respecto, Arenas et al. (1994) señalan que la tolerancia al ataque de insectos ha sido atribuida a factores como dureza, tamaño y textura del grano, contenido de amilosa, contenido de fenoles, presencia de sustancias antialimenticias y ácidos felúrico y cumárico, así como al espesor del pericarpio y al contenido de humedad. 
Ramírez (1987) y Ramírez y Silver (1983) observaron mayor daño en variedades de maíz con baja dureza en el pericarpio y altos contenidos de lisina y triptofano. García et al. (2005) encontraron diferencias preferenciales por los gorgojos y las palomillas entre razas y entre variedades; siendo las más preferidas las variedades de la raza Tuxpeño, a la cual pertenecen los genotipos evaluados; en comparación con las razas Chalqueño, Cónico y Bolita; aunque ninguna de las variedades de su estudio presentó tolerancia al ataque de insectos, dado que todas mostraron muy bajo porcentaje de grano sano en el último muestreo. En las regiones tropicales los gorgojos causan pérdidas considerables, debido a que la cosecha permanece en el campo, por la dificultad para su secado, hasta que presenta entre 12 a $14 \%$ de humedad, representando mucho tiempo de exposición al insecto, donde recibe la infestación que luego se incrementa rápidamente bajo condiciones de almacenamiento.

Los gorgojos adultos son de color café o casi negros, miden cerca de cuatro milímetros de largo; infestan el grano tanto en el campo como en el almacén, ya que pueden vivir de cuatro a cinco meses. Tanto las larvas como los adultos se alimentan del grano. La hembra adulta hace un hueco en el grano, deposita un solo huevo por grano y lo cubre con un fluido gelatinoso. Durante su ciclo de vida una hembra puede depositar de 300 a 550 huevos, los cuales incuban en tres días y originan una larva blanca y suave de tres milímetros (Tinoco et al. 2002).

En la búsqueda de genotipos con tolerancia a gorgojos, con buen potencial de rendimiento, adecuadas características agronómicas y con adaptación a la región tropical húmeda, se condujo un ensayo uniforme de híbridos y variedades de maíz con los siguientes objetivos: 1. Conocer el comportamiento productivo de genotipos de maíz y su respuesta a la presencia de Sitophilus spp bajo condiciones naturales de infestación en campo y almacén; 2. Determinar el efecto del tiempo de exposición del maíz en campo con respecto al daño causado por gorgojos.

\section{MATERIALES Y MÉTODOS}

La investigación se realizó durante los años 2002 y 2003, en el Campo Experimental Cotaxtla, perteneciente al INIFAP, el cual presenta un clima cálido húmedo Aw1, con temperatura media anual de $25^{\circ} \mathrm{C}$ y precipitación de $1.400 \mathrm{~mm}$. Consistió de un ensayo formado con 19 genotipos, híbridos y variedades comunes y de alta calidad de proteína (Cuadro 1). Se usó un diseño de bloques al azar con dos repeticiones, en parcelas de seis surcos de cinco metros, separados a $80 \mathrm{~cm}$, sembrando dos semillas por golpe para dejar una planta cada $20 \mathrm{~cm}$ y obtener una densidad de 62.500 plantas/ha.

Cuadro 1. Híbridos y variedades sometidos a evaluación de daños por gorgojos. Campo Experimental. Cotaxtla, INIFAP. Veracruz, México. 2002-2003.

\begin{tabular}{clccllc}
\hline Trat & Genotipo & $\begin{array}{c}\text { Nivel } \\
\text { proteí- } \\
\text { nico }\end{array}$ & Trat & Genotipo & $\begin{array}{c}\text { Nivel } \\
\text { proteí- } \\
\text { nico }\end{array}$ \\
\hline 1 & H-519C & QPM & 11 & SINT 1 QPM & QPM \\
2 & H-553C & QPM & 12 & SINT 2 QPM & QPM \\
3 & H-558C & QPM & 13 & SINT 3 QPM & QPM \\
4 & H-563C & Común & 14 & SINT 4 QPM & QPM \\
5 & H-520 & Común & 15 & SINT 1 QPM & QPM \\
& & & & CIM & & \\
6 & SINT LPS & Común & 16 & SINT 2 & QPM & QPM \\
& & & & CIM & & \\
7 & V-556AC & QPM & 17 & VS-536 & Común \\
& & & & & & \\
8 & V-538C & QPM & 18 & CRIOLLO & Común \\
9 & V537C & Común & 19 & SINT. SEQUÍA & Común \\
& COMP 1 & & & & & \\
10 & V-537C & Común & & & & \\
\hline
\end{tabular}

Las variables medidas fueron: altura de planta, altura de mazorca, aspecto de planta, sanidad de planta, acame, días a floración masculina, mala cobertura, aspecto de mazorca, sanidad de mazorca, mazorcas podridas, rendimiento de grano, mazorcas dañadas por gorgojos en campo y almacén e intensidad del daño. Las variables de aspecto y sanidad se calificaron mediante una escala de uno a cinco, con base en su uniformidad en tamaño, llenado de grano y presencia de pudriciones, donde uno corresponde a lo mejor y cinco a lo peor. Para la medición de variables en campo, la cosecha se realizó en un surco de cada parcela por mes, iniciando en noviembre a los 120 días después de la siembra y terminando en marzo. Con el fin de evaluar la respuesta al daño bajo condiciones de almacén, 
se hicieron observaciones a los $30,60,90,120,150 \mathrm{y}$ 180 días transcurridos a partir de la cosecha.

De esta manera se calculó el porcentaje de daño, con base en la cantidad de mazorcas dañadas, así como el promedio de daño dentro de las mazorcas afectadas en cada genotipo ( $0 \%$ correspondió a mazorcas sanas y $100 \%$ a mazorcas completamente dañadas). Se hicieron análisis de varianza individuales para las variables en estudio y la prueba de separación de medias usando la DMS al 0,05 y 0,01 de probabilidad; así como el análisis de correlación para las variables porcentaje de mazorcas con mala cobertura y porcentaje de daño por gorgojo, utilizando los datos de la última fecha de cosecha.

\section{RESULTADOS Y DISCUSIÓN}

Los valores medios de las características agronómicas y del rendimiento de los genotipos evaluados; así como los cuadrados medios del error para cada variable se muestran en el Cuadro 2. No se encontraron diferencias estadísticamente significativas en altura de planta. Los genotipos presentan poca variación, dentro de un rango de alturas que han sido seleccionadas previamente de acuerdo a las necesidades de la región, ya que su porte intermedio o bajo les confiere resistencia al acame provocado por los vientos. La calificación visual del aspecto de planta, que contempla vigor, carga y sanidad, no presentó diferencias estadísticas, mostrando calificaciones buenas e intermedias, muy similares entre genotipos. El porcentaje de acame resultó significativo, siendo los genotipos más afectados Criollo Chaneque, VS-536 y V-556AC, con 66, 47 y $46 \%$, respectivamente; lo cual es debido a que son los genotipos con mayor altura de planta, sobre todo el material criollo. La variable días a floración masculina, no presentó diferencias estadísticas, ya que la floración se presentó de manera muy uniforme, con una variación máxima de cuatro días, lo que muestra

Cuadro 2. Características agronómicas y rendimiento en genotipos de maíz común y de alta calidad de proteína. Campo Experimental Cotaxtla, INIFAP. Veracruz, México. 2002.

\begin{tabular}{lcccccccrr}
\hline \multicolumn{1}{c}{ Genotipos } & $\begin{array}{c}\text { Altura de } \\
\text { planta }\end{array}$ & $\begin{array}{c}\text { Aspecto } \\
\text { planta }\end{array}$ & $\begin{array}{c}\text { \% de } \\
\text { acame }\end{array}$ & $\begin{array}{c}\text { Floración } \\
\text { masculina }\end{array}$ & $\begin{array}{c}\text { \% mala } \\
\text { cobertura }\end{array}$ & $\begin{array}{c}\text { Aspecto } \\
\text { mazorca }\end{array}$ & $\begin{array}{c}\text { Sanidad } \\
\text { mazorca }\end{array}$ & $\begin{array}{c}\text { \% de } \\
\text { pudrición }\end{array}$ & $\begin{array}{c}\text { Rend. } \\
\text { tha }\end{array}$ \\
\hline H-520 & 226 & 1,25 & 23 & 52 & 2,3 & 2,3 & 1,8 & 0 & $7,93 *$ \\
SINT-9 & 218 & 2,5 & 23 & 53 & 11 & 2,3 & 1,8 & 1,3 & $7,11^{*}$ \\
H-553 C & 220 & 2,5 & 30 & 54 & 4,8 & 2,3 & 2,3 & 0,5 & $7,01^{*}$ \\
H-363 C & 237 & 2,75 & 26 & 55 & 2,3 & 1,5 & 1,8 & 2,3 & $6,68 * *$ \\
VS-536 & 242 & 2 & 47 & 53 & 1,8 & 1,5 & 1,8 & 0 & $6,58^{* *}$ \\
SINT1Q & 237 & 2,5 & 22 & 52 & 7,4 & 2,3 & 2,5 & 3,5 & $6,46^{* *}$ \\
H-519 C & 239 & 1,5 & 21 & 54 & 1,7 & 1,8 & 1,8 & 0 & $6,44 * *$ \\
V-537 C & 212 & 2,5 & 25 & 53 & 7,2 & 2,5 & 2,5 & 7,8 & 5,99 \\
V-556 AC & 220 & 2,75 & 46 & 52 & 9,7 & 2,5 & 2,5 & 5,4 & 5,92 \\
SINTLPS & 243 & 2,5 & 28 & 55 & 3,8 & 2 & 2 & 1,9 & 5,77 \\
SINT 3 QPM & 201 & 2,25 & 15 & 56 & 9,9 & 2,8 & 2,5 & 1,9 & 5,38 \\
H-558 C & 189 & 2,75 & 31 & 54 & 11 & 2,5 & 2,5 & 2 & 5,38 \\
SINT 4 QPM & 207 & 2,5 & 26 & 54 & 18 & 2,3 & 1,8 & 0 & 5,25 \\
SINT 2 Q & 243 & 2 & 20 & 53 & 8,6 & 2,3 & 2 & 1,5 & 5,18 \\
SINT 2 QPM & 209 & 3 & 9,6 & 54 & 17 & 2,8 & 2,3 & 6,6 & 5,03 \\
CRIOLLO CH. & 270 & 3 & 66 & 57 & 5,6 & 2,5 & 2 & 1,1 & 4,61 \\
V-538 C & 214 & 2,75 & 37 & 52 & 2,2 & 2,8 & 2,8 & 4,5 & 4,53 \\
V-537C COMP 1 & 222 & 2,75 & 20 & 53 & 6,3 & 2,3 & 2,5 & 11 & 4,09 \\
SINT 1 QPM & 222 & 2,75 & 15 & 54 & 3,5 & 2,8 & 2,3 & 4,7 & 3,63 \\
PROMEDIO & 225 & 2,46 & 28 & 53,9 & 7 & 2,3 & 2,2 & 2,9 & 5,73 \\
DMS 0,05 & 39 & 0,8 & 2,4 & 2,4 & 0,5 & 0,8 & 0,1 & 1,6 & 1,03 \\
DMS 0,01 & 53 & 1,8 & 3,2 & 3,3 & 0,6 & 1,1 & 1,2 & 2,2 & 4,41 \\
\hline CME & 340,13 & 0,14 & 1,27 & 1,3 & 0,05 & 0,14 & 0,16 & 0,58 & 0,24 \\
\hline
\end{tabular}

* Significancia de los tratamientos al 0,05 de probabilidad.

** Significancia de los tratamientos al 0,01 de probabilidad. 
que todos los genotipos son muy similares en cuanto a su ciclo vegetativo.

El porcentaje de cobertura presentó diferencias altamente significativas, de acuerdo al análisis de varianza. Con valores de 2,3\% y menores, sobresalieron H-519C, VS-536, V-538C, H-520 y H-363C. Se pueden observar en este grupo tanto genotipos comunes como de alta calidad de proteína. La cobertura es un factor que influye en la presencia de daños por gorgojos en su infestación en campo, ya que de acuerdo con Ramayo (1983), la mala cobertura facilita la entrada del insecto y el inicio de los daños, desde que el grano se encuentra en estado lechoso. Se observó alto grado de correlación entre las variables cobertura y porcentaje de grano con daños, $\mathrm{r}=$ 0,7 ; resultando más afectados los materiales con mayores porcentajes de mazorcas con mala cobertura.

Las variables aspecto, sanidad y pudriciones de mazorca, no presentaron diferencias significativas, observándose buen comportamiento y condiciones similares y uniformes en todos los genotipos. En el rendimiento de grano se encontraron diferencias altamente significativas entre genotipos, observándose un grupo superior formado por siete materiales, de los cuales por su rendimiento y por sus características sobresalen con superioridad H-520, Sintético 9, H-553C, H-363C, VS-536, Sintético1Q y H-519C, con rendimientos que van de 7,9 a 6,4 t/ha; aunque el Sintético1Q presenta cobertura un tanto deficiente. Se observa que este grupo sobresaliente está formado tanto por genotipos comunes, como de alta calidad de proteína.

En el avance de daños por gorgojos, en las diferentes fechas de cosecha se observó que a medida que el maíz permanecía más tiempo en campo se incrementaba el daño; pasando de 0,34 de la mazorca cosechada en noviembre, a 48,51 \% de daño para la cosecha de marzo. Los genotipos con menor grado de daño fueron H-363C, V-556AC, H-519C y VS-536 con niveles de mazorcas dañadas entre 32 y $38 \%$; resultando los más afectados V-538C y H-553C, con 65 y $68 \%$, respectivamente.

En los Cuadros 3, 4 y 5 se observa que existen diferencias preferenciales por los gorgojos entre híbridos y variedades de maíz, presentándose daños tanto en maíces comunes como en los de alta calidad de

Cuadro 3. Proceso de avance en la infestación por gorgojos, en función del tiempo de almacenamiento de mazorcas. Campo Experimental Cotaxtla, INIFAP. Veracruz, México. 2002-2003.

\begin{tabular}{llllllc}
\hline \multirow{2}{*}{ Genotipo } & \multicolumn{7}{c}{ Promedio para cada mes de evaluación } \\
\cline { 2 - 6 } & Dic & Ene & Feb & Mar & Abr & May \\
\hline H-363 C & 0,07 & 0,08 & 0,61 & 7,89 & 26,67 & 31,93 \\
V-556 AC & 0 & 0,43 & 0,98 & 9,00 & 28,48 & 35,00 \\
H-519 C & 0,19 & 0,14 & 1,04 & 8,66 & 27,67 & 35,87 \\
VS-536 & 0 & 0,12 & 1,82 & 12,77 & 33,70 & 38,47 \\
SINT LPS & 0 & 0,19 & 1,42 & 15,00 & 40,40 & 38,91 \\
SINT 2 QPM CM & 0,14 & 0,19 & 1,14 & 11,51 & 20,72 & 39,00 \\
CRIOLLO CH. & 0,33 & 0,07 & 0,46 & 10,00 & 30,00 & 41,25 \\
SINT1QPM CIM & 0 & 3,97 & 6,22 & 32,22 & 41,27 & 42,00 \\
H-558 C & 0,36 & 1,41 & 2,17 & 30,20 & 57,50 & 44,00 \\
SINT 4 QPM & 0,56 & 1,67 & 1,62 & 29,90 & 40,59 & 48,00 \\
SINT 9 & 0,09 & 0,64 & 2,80 & 13,90 & 45,00 & 52,00 \\
H-520 & 0,18 & 0,06 & 1,73 & 20,00 & 36,66 & 53,30 \\
V-537 C Comp 1 & 0 & 0,50 & 2,52 & 27,60 & 54,33 & 54,00 \\
SINT 2 QPM & 0 & 0,47 & 1,97 & 30,80 & 48,27 & 55,00 \\
V-537 C & 3,22 & 1,78 & 1,73 & 38,25 & 60,00 & 57,50 \\
SINT 3 QPM & 0,75 & 0,49 & 2,76 & 40,00 & 62,50 & 60,00 \\
SIN 1 QPM & 0,03 & 0,71 & 1,32 & 25,65 & 49,50 & 62,50 \\
V-538 C & 0,49 & 3,25 & 5,00 & 46,20 & 69,50 & 65,00 \\
H-553 C & 0 & 0,22 & 2,45 & 41,31 & 65,03 & 68,00 \\
\hline PROMEDIO & 0,34 & 0,86 & 2,09 & 23,73 & 44,09 & 48,51 \\
\hline
\end{tabular}


Cuadro 4. Proceso y grado de infestación por gorgojos en por ciento de mazorcas afectadas. Campo Experimental Cotaxtla, INIFAP. Veracruz, México. 2002-2003.

\begin{tabular}{|c|c|c|c|c|c|c|c|c|c|c|c|c|c|c|c|}
\hline \multirow[t]{2}{*}{ Genotipo } & \multicolumn{5}{|c|}{ Cosecha del 12 de noviembre } & \multicolumn{5}{|c|}{ Cosecha del 12 de diciembre } & \multicolumn{5}{|c|}{ Cosecha del 13 de enero } \\
\hline & Ene & Feb & Mar & Abr & May & Ene & Feb & Mar & Abr & May & Ene & Feb & Mar & Abr & May \\
\hline $\mathrm{H}-553 \mathrm{C}$ & 0 & 2,94 & 80 & 90 & 90 & 0 & 0,17 & 70 & 90 & 90 & 0,65 & 3,87 & 29 & 70 & 90 \\
\hline V-537 C Comp 1 & 0,53 & 4,94 & 50 & 90 & 80 & 0,56 & 2,33 & 30 & 70 & 80 & 0,42 & 2,5 & 40 & 90 & 70 \\
\hline V-538 C & 1,39 & 7,78 & 70 & 100 & 90 & 1,43 & 3,05 & 50 & 90 & 90 & 6,92 & 9,23 & 60 & 80 & 60 \\
\hline SINT 3 QPM & 0,37 & 4,5 & 70 & 90 & 90 & 0,5 & 6 & 70 & 90 & 80 & 0,59 & 0,35 & 20 & 60 & 50 \\
\hline SINT 4 QPM & 3 & 4 & 60 & 80 & 80 & 1,18 & 2 & 60 & 80 & 90 & 0,83 & 0,08 & 8 & 30 & 40 \\
\hline $\mathrm{H}-558 \mathrm{C}$ & 0,41 & 2,33 & 50 & 90 & 70 & 1,33 & 2,4 & 60 & 80 & 80 & 2,5 & 3,75 & 5 & 50 & 40 \\
\hline SINT 2 QPM & 1,41 & 4 & 60 & 80 & 70 & 0 & 1,2 & 30 & 60 & 70 & 0 & 1,56 & 15 & 60 & 60 \\
\hline SINT LPS & 0,58 & 2,35 & 40 & 90 & 80 & 0 & 2,68 & 30 & 80 & 70 & 0 & 0,64 & 5 & 30 & 30 \\
\hline SIN 1 QPM & 0,12 & 2,16 & 60 & 90 & 90 & 0 & 1,13 & 15 & 40 & 80 & 2 & 2 & 25 & 60 & 70 \\
\hline H-520 & 0,19 & 1,36 & 50 & 80 & 70 & 0 & 1,83 & 5 & 20 & 60 & 0 & 2 & 5 & 10 & 30 \\
\hline V-556 AC & 1,3 & 1,22 & 30 & 70 & 60 & 0 & 2 & 10 & 20 & 60 & 0 & 0,71 & 5 & 50 & 40 \\
\hline SINT 2 Q & 0 & 2,94 & 40 & 70 & 70 & 0,56 & 1,33 & 5 & 20 & 70 & 0 & 0 & 3 & 6 & 40 \\
\hline H-519 C & 0,17 & 2,79 & 30 & 70 & 70 & 0,25 & 1,35 & 10 & 50 & 70 & 0 & 0 & 3 & 15 & 30 \\
\hline H-363 C & 0,23 & 1,72 & 30 & 70 & 70 & 0 & 0,56 & 5 & 50 & 60 & 0 & 0,17 & 3 & 8 & 20 \\
\hline CRIOLLO CH. & 0,22 & 1,13 & 30 & 70 & 80 & 0 & 0,71 & 5 & 20 & 60 & 0 & 0 & 5 & 15 & 20 \\
\hline V-537 C & 1,33 & 5,51 & 60 & 80 & 80 & 4 & 0,38 & 80 & 90 & 80 & 0 & 0,55 & 8 & 40 & 60 \\
\hline SINT 9 & 0,55 & 1,2 & 20 & 60 & 80 & 0,54 & 8,93 & 25 & 80 & 70 & 0,83 & 0,25 & 3 & 50 & 50 \\
\hline SINT1Q & 0 & 2,09 & 60 & 80 & 70 & 0,24 & 3,33 & 20 & 40 & 60 & 11,67 & 19,45 & 80 & 80 & 60 \\
\hline VS-536 & 0,37 & 3,71 & 30 & 70 & 70 & 0 & 3,57 & 30 & 80 & 80 & 0 & 0 & 3 & 10 & 30 \\
\hline
\end{tabular}

proteína. Ninguna de las variedades estudiadas presentó tolerancia al ataque de insectos, dado que todas las variedades mostraron bajo porcentaje de grano sano en el último muestreo.

En la Figura 1 se observa la tendencia de la infestación por gorgojos durante el período de almacenamiento, bajo condiciones naturales, donde todos los genotipos estuvieron igualmente expuestos. Se partió del momento de la cosecha en el mes de noviembre, con un daño de $1,5 \%$, manteniéndose en $1,8 \%$ a los 30 días después de la cosecha; luego mostró incrementos a los 60 y 90 días, con valores de 8,6 y 23,2\%; respectivamente a los 120,150 y 180 días, alcanzando niveles de infestación de 52,1; 76,6 y 76,8\%. Esto coincide con los momentos donde la temperatura fue mayor, lo que indica que al incrementarse la temperatura ambiente, durante el período de marzo a mayo, la presencia del gorgojo también incrementó. Esta tendencia coincide con los resultados de García et al. (2005), quienes observaron que la máxima infestación de gorgojos ocurrió a los 120 días, en mazorcas de maíz con bajo contenido de humedad, almacenadas a temperatura ambiente.
Cuadro 5. Avances de daños por gorgojos a través de su exposición en almacenamiento bajo condiciones naturales, Campo Experimental Cotaxtla, INIFAP, Veracruz, México, 2003.

\begin{tabular}{llcc}
\hline & \multicolumn{3}{c}{$\begin{array}{c}\text { Avance de daño (\%) en } \\
\text { muestreos bimestrales }\end{array}$} \\
\hline Genotipo & Enero & Marzo & Mayo \\
H-363 C & 0,10 & 12,67 & 50 \\
H-520 & 0,10 & 20,00 & 53,33 \\
V-556 AC & 0,40 & 15,00 & 53,33 \\
CRIOLLO CH, & 0,10 & 13,33 & 53,33 \\
H-519 C & 0,10 & 14,33 & 56,70 \\
SINT LPS & 0,20 & 25,00 & 60,00 \\
SINT 2 QPM CIMMYT & 0,20 & 16,00 & 60,00 \\
VS-536 & 0,10 & 21,00 & 60,00 \\
H-558 C & 1,40 & 38,33 & 63,30 \\
SINT/QPM CIM & 4,00 & 53,33 & 63,3 \\
SINT 2 QPM & 0,50 & 35,00 & 66,7 \\
SINT, SEQUÍA & 0,60 & 16,00 & 66,7 \\
SINT 4 QPM & 1,70 & 42,67 & 70,00 \\
SINT 3 QPM & 0,50 & 53,33 & 73,30 \\
V-537 C & 1,80 & 49,33 & 73,30 \\
V-537C Comp 1 & 0,50 & 40,00 & 76,70 \\
V-538 C & 3,20 & 60,00 & 80,00 \\
SIN 1 QPM & 0,70 & 33,33 & 80,00 \\
H-553 C & 0,20 & 59,67 & 90,00 \\
\hline
\end{tabular}




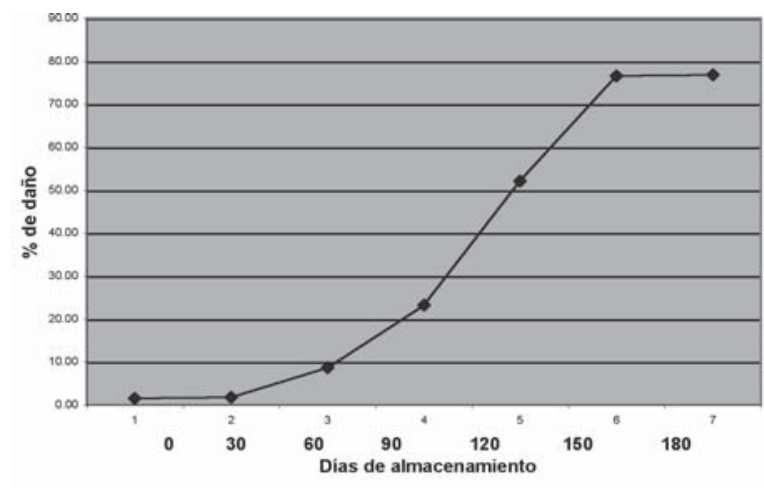

Figura 1. Avance mensual de daños por gorgojos en mazorca bajo condiciones de almacén.

El análisis de correlación determinó correlación positiva y altamente significativa $\left(\mathrm{r}=0,72^{* *}\right)$ entre las variables porcentaje de mazorcas con mala cobertura y porcentaje de daño por gorgojo. Esto sugiere que, para las condiciones tropicales, los genotipos deben tener buena cobertura de mazorca, en virtud de que la presencia de daño por gorgojo proviene desde el campo y ésta es mayor a medida que los maíces presentan deficiencias en su protección por el totomoxtle.

\section{CONCLUSIONES}

Los genotipos H-520 y Sintético Sequía, normales y H-553C de alta calidad proteínica sobresalen por su mayor rendimiento y menores porcentajes de mazorcas con mala cobertura.

El retraso en la cosecha incrementa significativamente el porcentaje de mazorcas dañadas por gorgojos. La mejor época de cosecha corresponde a los meses de noviembre a enero.

H-519C, H-363C y VS-536 fueron los genotipos menos dañados en campo.

H-363C y Sintético Sequía presentaron los menores porcentajes de daño en su grano bajo condiciones naturales de almacenamiento.

Existe correlación positiva y altamente significativa entre la mala cobertura de mazorca y el porcentaje de daño por gorgojos.
Existen diferencias preferenciales por los gorgojos entre genotipos de maíz, siendo afectados tanto híbridos y variedades comunes, como de alta calidad de proteína.

\section{LITERATURA CITADA}

Arenas, LC; Salinas, MY; Ballesteros, LJ; López, HA. 1994. Alternativas al uso de insecticidas. In: Perales, M; Fregoso, L. eds. Desarrollo sostenible de los agroecosistemas en el sur de Sinaloa. Ed. Multigraf S.A. de C.V., México. p. 217-226.

Beck, Sd. 1965. Resistance of plants to insects. Annual Review of Entomology 10: 207-232.

Betanzos, E. 1980. Selección y mejoramiento de variedades de maíz con alta calidad proteica por resistencia a insectos de granos almacenados. In: Moreno, E; Ramírez, M. eds. Memorias del Coloquio Internacional sobre conservación de semillas y granos almacenados. Instituto de Biología, UNAM. México, D. F. p. 366-387.

CIMMYT (Centro Internacional de Mejoramiento de Maíz y Trigo). 1999. The improvement and promotion of quality protein maize in selected developing countries. Folleto Misceláneo. 20 p.

García, ZE; Molina, JD; García, JJ. 2005. Dinámica poblacional y preferencia de gorgojos y palomilla en maíz almacenado con baja humedad del grano. Folia Entomológica. Mex. 44(2): 145-154.

Lagunas, TA; Domínguez, RR. 1985. Plagas del maíz. Universidad Autónoma Chapingo. Chapingo, Estado de México. 100 p.

Mc Gregor, LR. 1980. Los problemas sobre resistencia de granos al ataque de insectos del almacén en México. In: Moreno, E; Ramírez, M. eds. Memorias del Coloquio Internacional sobre Conservación de Semillas y Granos Almacenados. UNAM. México. 220 p.

Mertz, ET; Bates, LS; Nelson, OF. 1964. Mutant gene that changes protein composition and increase lisien content of maize endosperm. Sience 145: 279-280.

Ortega, CA, Cota, AO, Vasal, SK, Villegas, ME, Córdova, OH, Barreto, SMA, Wong, PJJ, Reyes, MCA, Preciado, ORE, Terrón, IA; Espinosa, CA. 2001. H-441, H-442 y H-469, híbridos de maíz de calidad proteínica mejorada 
para el Noroeste y Subtrópico de México. Folleto Técnico No. 41. INIFAP. México, 44 p.

Ramayo, RLF. 1983. Tecnología de granos. Universidad Autónoma Chapingo. Departamento de Industrias Agrícolas. Chapingo, Estado de México. 216 p.

Ramírez, M; Silver, JB. 1983. Deterioration and damage produced in corn grains in Mexico by Prostephanus truncatus Horn (Coleoptera: Bostrichidae). Biodeterioration 5: 583-591.

Ramírez, M. 1987. Almacenamiento y conservación de granos y semillas. 11 ed. Editorial Continental. 98 p.

Reyes, CP. 1971. Genotecnia del maíz para tierra caliente. Información histórica de la agricultura. Monterrey, Nuevo León. 138 p.
Tinoco, CA; Rodríguez, FA; Sandoval, JA; Barrón, FS; Palafox, CA; Esqueda, EV; Sierra, MM; Romero, MJ. 2002. Manual de producción de maíz para los estados de Veracruz y Tabasco. Guía Técnica Núm. 20. 113 p.

Vasal, SK; Villegas, ME; Bjarnason, M; Gelaw, B; Goertz, P. 1980. Genetic modifiers and breeding strategies in developing hard endosperm opaque-2 materials. In. Improvement of Quality Traits of Maize for Grain and Silage Use. London, U.K. p. 37-73.

Villacís, SJ; Sosa, MC; Ortega, CA. 1972. Comportamiento de Sitotroga cerealella Olivier (Lepid.: Gelechiidae) y de Sitophilus zeamais Motschulsky (Coleop.: Curculionidae) en diez tipos de maíz con características contrastantes. Revista Peruana de Entomología Agrícola 15(1): 153-164. 